East African Medical Journal Vol. 79 No. 12 December 2002

FACTORS INFLUENCING ACCEPTABILITY OF VOLUNTARY COUNSELLING AND TESTING FOR HIV IN BUSHENYI DISTRICT OF UGANDA F. Nuwaha, MD, PhD, Directorate of Health Services, Bushenyi District, P.O. Box 1, Bushenyi-Uganda, D. Kabatesi, MD, MPH, Sexually Transmitted Diseases clinic. Mulago Hospital, P.O. Box 7051. Kampala. Uganda, M. Muganwa, MD, MPH, Senior Lecturer, Institure of Public Health. Makerere University, P.O. Box 7052, Kampala, Uganda, C.C. Whalen, MD, MS, Associate Professor, Department of Epidemiology and Biostatistics, Case Western Reserve University. Cleveland. Ohio, USA

Request for reprints to: Dr. F. Nuwaha, P.O. Box 6924, Kampala, Uganda

\title{
FACTORS INFLUENCING ACCEPTABILITY OF VOLUNTARY COUNSELLING AND TESTING FOR HIV IN BUSHENYI DISTRICT OF UGANDA
}

\author{
F. NUWAHA, D. KABATESI, M. MUGANWA and C.C. WHALEN
}

\begin{abstract}
Objective: To understand the factors influencing choice of voluntary counselling and testing (VCT) for HIV with a view of suggesting measures for increased uptake.

Design: Focus group discussions were used to elicit reasons for carrying out VCT and a cross sectional survey to estimate the proportion of people who undertake VCT. Setting: Bushenyi district, Uganda.

Participants: A cluster random sample of 219 people and four purposively selected focus group discussions with 32 participants.

Main outcome measures: Elicited attitudinal beliefs, self-efficacy expectations, and social influences that are probably associated with VCT for HIV based on the Attitude Social influence self-Efficacy (ASE) Model. The proportion of people who had ever undertaken VCT for HIV was also determined.

Results: Thirty-eight(17\%) of the 219 people interviewed had ever undergone HIV. The factors influencing VCT for HIV were consequences of a test result, influences from a sexual partner, cost of VCT, physical accessibility of VCT, awareness, risk of HIV infection, need for linking VCT with care (especially availability of anti-retrovirals) and perceived quality of care of VCT services.

Conclusions: Increased mobilisation and access for VCT, reducing costs of VCT, linking of VCT with care, and emphasising the positive consequences of VCT as well as providing high quality VCT services may increase the number of people seeking VCT.
\end{abstract}

\section{INTRODUCTION}

In Uganda, the Human Immunodeficiency Virus (HIV) epidemic is now regarded as mature with about $10 \%$ of the population infected(1). There are worriers that some measures of HIV control in early epidemics may be radically different from the ones in well established mature epidemics(2). For example, whereas treatment of sexually transmitted diseases (STDs) may be important in early epidemics it may not be significant in mature epidemics $(3,4)$. Furthermore, evidence from Uganda show that as the HIV/AIDS epidemic matures, the proportion of casual sexual partnerships progressively decreases and HIV spread is mainly through regular sexual partnerships with discordant couples(4-8). This is a cause for concern as condom use (which is a major HIV control tool) may not be very appropriate for regular sexual partnerships, which are perceived to be safer(5). Moreover, one other reason for regular partnerships is the need for conception. Thus condom use alone may also not be very effective in preventing HIV infection among regular sexual partnerships and there is an urgent need to promote condom use alongside widespread voluntary counselling and testing (VCT) for $\operatorname{HIV}(2,5)$. It has been hypothesised that in mature epidemics where death due to HIV is common(9), people who test HIV sero-negative will jealously guard their sero-negative status(2). Besides, VCT is a crucial step towards the use of anti-retrovirals that greatly improves the quality of life among the HIV infected. There is thus need to understand the acceptability of VCT and the factors that influence the acceptability of testing for HIV. The understanding of these factors is a prerequisite for designing measures aimed at increasing the acceptability of taking an HIV test. It is also the first stop towards widespread use of VCT.

This work was aimed at understanding the factors influencing the acceptability of voluntary counselling and testing for HIV in a rural area of Uganda with a view of suggesting measures for increased VCT uptake. The research drew on a theoretical methodologythe Attitude-Social-Influence-Self efficacy (ASE-model) $(10,11)$. We have previously found this model useful in understanding and predicting various health behaviours including those related to HIV/AlUS/STDs in the Ugandan setting(12-15). 
The ASE-model: The Attitude-Social influenceself-Efficacy (ASE) model shown in figure 1 predicts various health behaviours $(10,11)$, including those related to HIV/AIDS/STDs)(15-18).

The ASE-model is comparable to the Planned Behaviour model (19). In the ASE-model, behaviour such as compliance with VCT for HIV is considered to be a result of behaviour intention. Furthermore, three main psycho-social factors have been identified that predict health related behaviour intention: attitudes, social influences, and self-efficacy. A person's attitude towards attendance for VCT for HIV is a result of the consequences that a person expects from VCT for HIV. Social influence is as a result of social norms relevant to VCT for HIV, support from important others to attend or not attend for VCT, and whether important others attend or do not attend for VCT themselves. Selfefficacy expectations can be seen as a person's belief of case to attend for VCT and the ability to cope with barriers that may hinder actual attendance. The implication of the model is that a person's health behaviour can be modified, by targeting attitudes, perceptions of social norms, social support, and selfefficacy expectations. According to the ASE-model "external variables", such as social-demographic factors, do not influence behaviour directly but rather through behavioural determinants and intention. Moreover, selfefficacy not only influences behaviour intention but also has a direct influence on behaviour $(10,11)$. Finally, previous behaviour, or trying to perform the behaviour, will lead to a feedback mechanism that may, in turn, influence the behaviour determinants(10). This model is important in behaviour as psychosocial variables can be changed to influence the behaviour whereas external variables are normally not changeable or easy to change.

\section{MATERIALS AND METHODS}

Both focus group discussions (FGDs) and individual interviews were used to collect the data. Sampling for FGDs was purposive and statistical sampling methods were used for individual interviews.

Study sites and population: The study was based in Bushenyi district of south-western Uganda. The Population of the district is about 800,000 people (spread over an area of $5396 \mathrm{~km}^{2}$ ) whose main source of income is subsistence agriculture. The population of Bushenyi is about $95 \%$ ruralbased. About $60 \%$ of the population are within one hour's walk of a public health facility. Administratively, Bushenyi district is divided into 5 counties 27 sub-counties (third level local councils-LC3), 161 parishes (LC2s) and 2052 villages (LCIs). The district is served by 3 hospitals (one public and two for non-governmental organisations (NGOs), 49 health centres, many private clinics and 215 immunisation posts. Voluntary counselling and testing for HIV is only available at Ishaka (one NGO hospital) and at Bushenyi medical centre (a private health centre). Both Ishaka hospital and Bushenyı Medical centre are located in Bushenyi town council. The cost of the VCT at these sites ranges between 6-10 US dollars.

Design: Four FGDs consisting of 8 participants (4 women 4 men) each were conducted. The FGDs were chosen strategically to represent variations in age and place of residence. One FGD was based in Bushenyi town. The other three were based in rural areas.

Two members of a research team, a moderator and an assistant using a pre-designed discussion guide collected data on FGDs. The moderator guided the FGDs whereas the assistant took care of audio-recording equipment. wrote down notes as well as non-verbal communication. Information was collected on HIV transmission and causation, advantages and disadvantages of undertaking voluntary counselling and testing for HIV, sources of social influence in VCT decisions, and on barriers and supports for undertaking VCT.

In the individual interviews 219 people were interviewed with a pre-designed pre-tested interview schedule. Data was collected on socio-demographic characteristics. willingness to

\section{Figure 1}

Attitude-Social influence self efficacy model for predicting behaviour

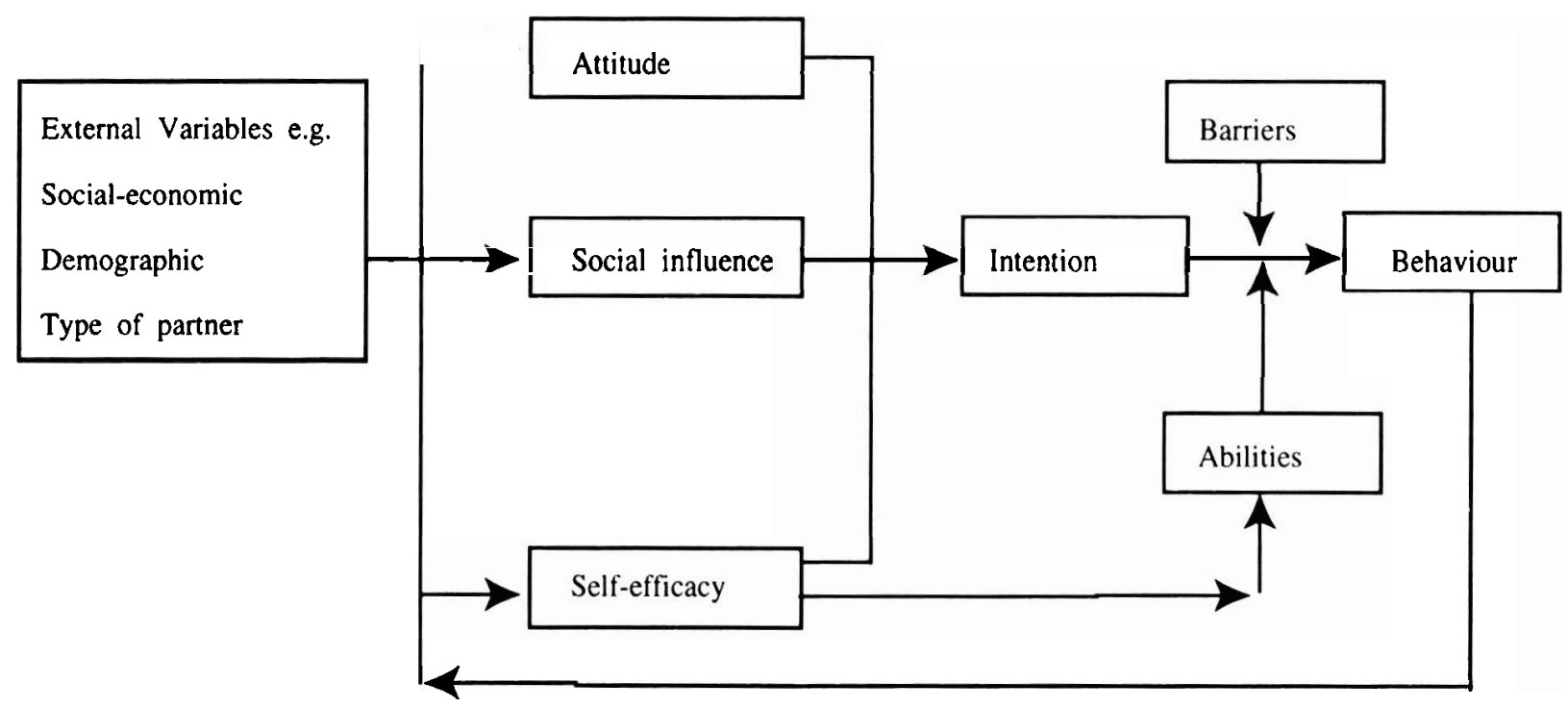


undertake VCT, experiences with VCT, sexual behaviour, type of sexual partnerships, attitudes towards VCT, perceived social influence towards VCT, perceived barriers and supports towards VCT and cues for undertaking VCT. The interview schedule comprised both open and closed questions.

Two research assistants (one woman and one man) carried out the FGDs and four research assistants ( 2 men and 2 women) carried out the individual interviews. The research assistants were trained for this purpose by one of the principal investigator (FN). All research assistants spoke the main languages used in the interviews and FGDs.

Statistical issues and sampling: For the FGDs the sampling was purposeful and strategic. For the individual interviews, the sample size was based on that required to determine the prevalence in the population of those willing to undertake VCT with a $5 \%$ level of significance and $80 \%$ power. The sampling used was adapted from the World Health Organisation Expanded Programme on Immunisation (EPI) cluster sample (20). Thirty clusters of seven homes with at least an adult who is between 18-59 years were chosen randomly from a listing of all LCls in Bushenyi district using a table of random numbers. Starting in the centre of the LCls, a stick was spun and the interviewers followed that the direction of the stick. Individuals for interviews (one per home) were chosen at random from all those who were at home at the time of the interview. If a home did not have an adult aged 18-59 years a neighbouring home was included.

\section{ANALYSIS}

Analysis of FGDs included verbatim transcribing of the tapes. The raw data from the tapes and the notes was then transformed in a well-organised set of information. After the transformations of the raw data, it was ordered in relation to the discussion topics. Then it was summarised by listing the data that belong together. In order to gain insight about VCT behaviour concepts that people use to explain their views were looked at.

In the individual interviews analysis included sorting and ordering of responses, which were then grouped and summarised. Statistical analysis was with the Chi-square $\chi^{2}$ or Fisher's exact test, which were used to test differences between men and women. For all the analysis a P-level of five percent with Yates's corrected $\chi^{2}$ of two-tailed T-test were used. Computer software SPSS/PC (21) was used in the analyses.

Ethical clearance: The Uganda AIDS sub-committee of the National Council for Science and Technology and the institutional review boards of the Case Western Reserve University and National Institute of Health USA approved the study. Permission to conduct the field research was sought from Bushenyi health district offices. Subjects were only enrolled in the study after informed consent has been obtained.

\section{RESULTS}

The findings from the FGDs and the individual interviews are presented in an integrated manner. Where appropriate, note is made regarding agreement or lack of such between the two sources of information.

Four focus groups of eight members each (four women and four men) were conducted. The individual interviews were conducted with 219 people (82 women and $137 \mathrm{men}$ ). The ages of the 219 people that were interviewed individually ranged from 18-60 years with a mean age of 29 (standard deviation 11) years for women and 30 (SD 9) years for men. Of the sample $71(32.4 \%)$ were never married, $122(56.2 \%)$ were in monogamous relationships, $20(9.1 \%)$ were in polygamous relationships and $5(2.3 \%)$ were either widowed, separated or divorced. Eighteen of the 219 people $(8.2 \%)$ had never attended school, 120(50.2\%) had attended primary level, $80(36.5 \%)$ had attended up to secondary level, and $11(8.2 \%)$ had tertiary education. Only $19(8.7 \%)$ were urban dwellers and $125(57 \%)$ were subsistence farmers. Regarding sexual behaviour, $23(10.5 \%)$ had not engaged in sexual intercourse in the previous one year, $114(52.1 \%)$ had sex with only one sexual partner, and $82(37.4 \%)$ had had sex with more than one sexual partner. Thirty seven of the respondents (16.9\%) did not have a regular partner, $158(72.1 \%)$ had one regular partner and $24(11 \%)$ had more than one regular partner. One hundred forty three $(65.3 \%)$ had not had sex with a casual partner in the previous one year, $23(10.5 \%)$ had had sex with one casual partner and 53(24.2\%) had had sex with more than one casual partner in the previous year. Eighty four (38.4\%) had ever paid or been paid for sex in cash or kind, $69(31.5 \%)$ had ever suffered from a STD, 115(52.5\%) never used a condom in their life, 34(15.6\%) always used a condom and $126(57.5 \%)$ accepted a free supply of condoms offered during the interviews.

Knowledge and experience of Voluntary Counselling and Testing: In all the FGDs, HIV/AIDS/ STDs were mentioned spontaneously as major public health problems responsible for significant morbidity and mortality. The causation/modes of transmission (sexual intercourse, mother to child and through contaminated blood) of HIV/AIDS, were also well articulated. The symptoms of AIDS such as diarrhoea, prolonged fever, loss of weight, herpes zoster, recurrent boils, darkening of skin, change of hair and psychosis were easily cited. However, the issue of asymptomatic HIV only came into the discussion of the FGDs after probing and still asymptomatic infection appeared not certain/clear with the majority of the FGD participants. There were expectations, however, as the following quote from one FGD participant illustrates "This AIDS is confusing, sometimes you see a fat lady without any symptoms yet your are sure she must be infected because she has killed at least five men". Other participants in the same FGD, especially men appeared to nod in agreement. In the same urban based FGD, voluntary counselling and testing was mentioned as the only sure way of "proving" that one is actually infected with HIV. All places that offer VCT in Bushenyi district and the neighbouring Mbarara district (i.e. Ishaka hospital, Bushenyi Medical Centre, Mbarara hospital, and the Mbarara AIDS information centre) 
were mentioned in all the FGDs. Among the reasons mentioned for undergoing VCT were: showing symptoms of AIDS; loss of sexual partner; for marriage; mandatory requirements like joining the army, when one is to get a scholarship, when demanded by a sexual partner, and after undergoing various risk behaviours such as unprotected sex with somebody you don't trust, undergoing blood transfusion, and after being involved in a road traffic accident.

In the individual interviews, $38(17.4 \%)$ of the 219 people interviewed had ever undergone an HIV test. Of the 38 participants 36 had received their results and of these nine $(25 \%)$ tested positive for HIV. The reasons for testing in the thirty eight are shown in Table 1.

\section{Table 1}

Reasons for undertaking Voluntary Counselling and Testing for HIV $(n=38)$

\begin{tabular}{lcc}
\hline Reason & No. & $\%$ \\
\hline AIDS related symptoms & 24 & 63 \\
Worried about risky sexual behaviour & 18 & 47 \\
Marriage & 8 & 21 \\
Death of sexual partner & 6 & 16 \\
Others (blood donation, getting & 3 & 8 \\
$\quad$ scholarship, joining the army) & & \\
\hline
\end{tabular}

NB: Some respondents gave more than one reason

Regarding intention to test in the next one year (if the facilities were accessible), 140(63.9\%) said they were likely to undertake the test, $61(27.6 \%)$ said they were unlikely and $18(8.2 \%)$ said that they were not sure.

The factors influencing acceptance of VCT for HIV are considered under attitudinal beliefs, social influence, self-efficacy, awareness, and risk of infection with HIV.

Attitudinal beliefs: In the FGDs it was said that positive consequences of VCT would encourage testing such as: encouraging of positive living like eating a good diet, stopping smoking, drinking and "generally caring about your health"; planning for one's future as in making decisions about marriage and having children. Planning treatment if one has the means was also echoed as a benefit. Other positive consequences mentioned were gaining confidence in life with what one does, and practising safer sex or abstinence. It was said that if one was found negative there is greater likelihood of adopting safer sexual practices or abstinence so as to jealously guard one's seronegative status. A common echo was "you would be foolish to infect yourself after knowing that your are negative". It was also said that some people after testing become goodwill ambassadors in encouraging others to test and also protect themselves and others against infection.
On the other hand it was said that anticipated consequences of being found positive would discourage HIV testing. Among the negative consequences mentioned were: loss of hope leading to destructive behaviour, early death through worries, and sometimes suicide. "It may be better not to know your status and you live longer" was a common expression. It was also mentioned in all FGDs that once people are found positive they may decide not to "die alone" and may deliberately spread the HIV. Other negative consequences of VCT mentioned included stigma from society and rejection from friends, relatives, and sexual partners. In the individual interviews, people were asked the advantages and disadvantages of undertaking VCT. (Table 2.) Women were more likely to mention rejection whereas men were more likely to mention suicide.

Social influence: It was said that the decision to undertake VCT is mainly a personal individual decision. However, the decision was also said to be influenced by other people ("important others"), such as spouses, sexual partners, prospective marriage partners, relatives, friends, health workers/counsellors, religious leaders, political leaders and those that have undergone VCT in the past. In the individual interviews the people were asked the most likely source of influence on decision of VCT (Table 3).

It appears that about three quarters of the people said that they would influence the decision to undergo HIV test by themselves. It was interesting that sex never appeared to have influence on this decision $\left(\chi^{2}=\right.$ $0.49,1$ degree of freedom and P-level $=0.39$ ).

Self-efficacy, barriers and supports: Among the problems mentioned with VCT were that testing centres were too far especially if coupled with poor means of communication/transport as in rural areas. The services were also said to be expensive and out of reach of many people especially the youth and women. Poor perceived quality of care was also articulated as a barrier in form of time taken to give the results (many people preferred one day result), long waiting time before VCT, confidentiality and secrecy in handling of the results. The issue of sensitivity and specificity of the results were also mentioned anticipating the danger and consequences of labelling one HIV positive where as not.

When FGDs participants were asked about what can be done to increase the number of people undertaking VCT, the mentioned responses were: bring services nearer to the people; provide free services, and offer help (especially with anti-retroviral drugs) to those found to be HIV positive. A common expression was "what is the use of VCT if one cannot manage the very expensive AIDS drugs"

In the individual interviews people were asked what could be done to make more people undergo VCT (Table 4). 
Table 2

Attitudinal beliefs concerning Voluntary Counselling and Testing for HIV

\begin{tabular}{ccccc}
\hline Attitudinal belief & Women & Men & $\mathrm{X}^{2}(\mathrm{df})$ & P-level \\
& $\mathrm{n}=82$ & $\mathrm{n}=137$ & & \\
& No.(\%) & No.(\%) & & \\
\hline
\end{tabular}

Percent who agree that my testing for HIV will:

\section{Advantages}

Encourage positive living if infected

Lead to better future planning

Lead to confidence in life

$36(43.9)$

$32(39.0)$

Encourage preventive behaviour

$27(32.9)$

$37(45.1)$

Disadvantages

Easier spread of disease if positive

Suicide,

Earlier death due to worries

Stigma

Rejection

Unnecessary worries

$20(24.2)$

$5(6.0)$

$77(94.0)$

$15(18.2)$

$16(19.5)$

$31(38.8)$

\begin{tabular}{ccc}
$52(38.0)$ & $0.75(1)$ & 0.38 \\
$67(48.9)$ & $2.02(1)$ & 0.15 \\
$56(40.9)$ & $1.37(1)$ & 0.24 \\
$48(35.0)$ & $2.20(1)$ & 0.13 \\
& & \\
$38(27.7)$ & $0.29(1)$ & 0.58 \\
$21(15.3)$ & $4.12(1)$ & 0.04 \\
$116(84.6)$ & $0.18(1)$ & 0.74 \\
$14(10.2)$ & $2.91(1)$ & 0.09 \\
$10(7.3)$ & $7.31(1)$ & 0.007 \\
$62(45.3)$ & $1.17(1)$ & 0.28 \\
\hline
\end{tabular}

\section{Table 3}

Sources of Social influence for Voluntary Counselling and Testing for HIV

\begin{tabular}{lcccc}
\hline Source of influence & $\begin{array}{c}\text { Women } \mathrm{n}=82 \\
\text { No. (\%) }\end{array}$ & $\begin{array}{c}\text { Men N=137 } \\
\text { No. (\%) }\end{array}$ & X $(\mathrm{df})$ & P-Level \\
\hline $\begin{array}{l}\text { Decision to undertake VCT likely } \\
\text { to be influenced by: }\end{array}$ & & & \\
Myself & $60(73.2)$ & $62(85.2)$ & $0.49(1)$ & 0.39 \\
Sexual partner & $39(47.6)$ & $52(45.3)$ & $1.94(1)$ & 0.16 \\
Relatives & $10(12.2)$ & $10(7.3)$ & $1.48(1)$ & 0.22 \\
Friends & $5(6.1)$ & $23(16.8)$ & $5.25(1)$ & 0.02 \\
Health care workers & $13(15.9)$ & $30(21.9)$ & $1.19(1)$ & 0.27 \\
Somebody who has tested & $2(2.4)$ & $6(4.4)$ & $\mathrm{F}_{0.54(1)}$ & 0.45 \\
\hline
\end{tabular}

df. degrees of freedom; F Fisher's exact test

Table 4

Supports and barriers towards Voluntary Counselling and Testing for HIV

\begin{tabular}{lcccc}
\hline Support/barrier & $\begin{array}{c}\text { Women } \\
\mathrm{n}=82 \\
\text { No. (\%) }\end{array}$ & $\begin{array}{c}\text { Men } \\
n=137 \\
\text { No. (\%) }\end{array}$ & $\mathrm{X}^{2}$ (df) & P-Level \\
\hline $\begin{array}{l}\text { It would be easier for me to } \\
\text { undertake VCT if: }\end{array}$ & $50(61)$ & $95(69.3)$ & $1.60(1)$ & 0.20 \\
$\begin{array}{l}\text { Those positive are helped with } \\
\text { anti-retroviral drugs }\end{array}$ & $37(45.1)$ & $57(41.6)$ & $0.25(1)$ & 0.61 \\
$\begin{array}{l}\text { Testing Centres are near } \\
\text { Results are secret }\end{array}$ & $9(11)$ & $15(10.9)$ & $0.01(1)$ & 0.99 \\
$\begin{array}{l}\text { Free services are provided } \\
\text { Legal requirement }\end{array}$ & $47(57.3)$ & $78(56.8)$ & $0.003(1)$ & 0.96 \\
Others & $1(1.2)$ & $1(0.7)$ & $F_{0.14}(1)$ & 0.71 \\
\hline
\end{tabular}

df. degrees of freedom; FFisher's exact test 
Other two issues emerged from the FGDs and individual interviews that were considered very important and are therefore described separately. These issues were labelled Awareness and Risk of HIV infection.

Awareness:In the FGDs it was said that lack of awareness on the need for VCT reduces the number of people undertaking VCT. It was reportedly said that among the strategies for HIV control the government had never encouraged people to undertake VCT. “...May be they fear the consequences of testing", otherwise. why haven't I heard a lot of campaign for testing on Radio," was one expression in one of the FGDs. In improving the percentage of people who would undertake VCT people suggested increased mobilisations, and campaigns through the famous FM radio stations, and through seminars/workshops.

Risk of HIV infection: Another issue that seemed important in VCT was the perceived risk of HIV infection. In the FGDs it was said that people who considered themselves at increased risk of HIV infection were more likely to undertake an HIV test. Similarly it was said that people at low risk of HIV infection were less likely to consider HIV testing. However most people in FGDs appeared to underestimate their risk of HIV infection, for example by saying that they can choose partners carefully such as those not infected (e.g. fat ones).

In the individual interviews people were asked to estimate their risk being infected with HIV in the coining one year. Of the 219 people, 50(23\%) said they had no chance of being infected, $88(40 \%)$ said their chance is either very small or small, $67(30 \%)$ said their chance is either big or very big, $9(4 \%)$ said they are already infected, $3(2 \%)$ said they could not access the risk, whereas data for $2(1 \%)$ was missing. Sex of respondent did not influence the estimated perceived risk of acquisition of HIV (Fishers exact test 9.9, 7 degrees of freedom, $\mathrm{P}=0.19$ ), It was interesting to note that intention to test for HIV in next one year was positively correlated with perceived risk of HIV infection (Pearson's correlation coefficient $r=0.28 \quad \mathrm{P}<0.001$ ).

\section{DISCUSSION}

In this study two research methods namely FGDs and individual interviews were used to generate information on factors influencing the acceptability of voluntary counselling and testing for HIV in a rural area of Uganda. The FGDs enabled us to explore and elicit the various beliefs and the individual interviews enabled us to determine the prevalence of elicited beliefs among the population. Thus in this study these two data sources complemented each other with information from FGDs mainly collaborated by findings from the individual interviews. These methods have also been found useful in illuminating indigenous knowledge systems in relation to AIDS and STDs, and shedding light on sexual as well as health seeking behaviour $(10,22)$. Compared to a quantitative survey, qualitative methods produce a richer amount of data. Qualitative methods also enable a researcher to identify subtle differences in responses, and ask follow-up questions for clarification immediately based on the responses given $(23,24)$. Compared to personal interviews, FGDs allow respondents to react and build on responses of other group members. This process may result in data that would otherwise remain uncovered. The inclusion of women and men in the FGDs did not inhibit the expression of either sex and could have actually stimulated the discussions. As regards some issues where men were particularly deemed responsible, the women often referred to them, with expressions as "you men".

This study revealed that a number of different issues based on the ASE-model seemed to be important for choosing to undertake or not undertake VCT. Generally, most participants articulated both the positive and negative consequences of VCT. Most of the positive consequences were linked to a negative test whereas most of the negative consequences were linked to a positive result. This means that in order to increase the number of people choosing to undertake VCT, there is need to emphasise the positive consequences of VCT and put measures in place to counteract or address the perceived negative consequences of VCT. Since the majority of the people (about 75\%) who undergo VCT will be negative emphasising this factor in health education/promotion may be effective in encouraging VCT

Social pressure especially from sexual partners friends and relatives emerged important in influencing VCT decisions. This suggests that these "important others" as suggested by Kleinman et al(25) need to be involved in health education about voluntary counselling and testing for HIV. Sexual partners of people appeared particularly important as determinants of whether individuals choose VCT and this was not surprising given the high proportion of regular sexual partnerships in the sample as has been observed elsewhere (2,5-7). This means that any measures aimed at encouraging VCT in addition to taking individual perspectives may also need to plan services for couples. It was interesting that about three quarters of people in this study said the decision for VCT depended much on themselves where as the other half, said it may depend on important others. This in practice means that to improve the proportion of people undertaking VCT, mobilisation will have to target individuals as well as their "important others" especially sexual partners.

Very important barriers and supports were identified that could encourage or discourage VCT for HIV. The most important of these were inked to access of VCT services through (reducing distance to VCT centres, providing free or subsidised services), increasing awareness, perceiving of personal risk, linking VCT with care (especially availability of anti-retrovirals); and improving quality of care especially in providing confidentiality in VCT centres. These issues are potential 
areas for remedial action as genuine improvements can be made in the majority of them. The issue of making anti-retroviral drugs more affordable deserves utmost attention as a measure to increase the number of people seeking VCT. More help for people infected with HIV could also be through other means such as: anti-TB prophylaxis, treatment of opportunistic infections, and counselling to reduce destructive behaviour, rejection and stigma. The linking of VCT with care for AIDS and other diseases also appears critical since most people choose VCT for perceived AIDS related symptoms that could be due to other diseases.

Another important issue that could improve VCT is to encourage VCT before any AIDS related symptoms appear. Lay people need to understand that it takes a long time from infection with HIV to appearance of AIDS symptoms, and that most of the benefits of VCT accrue from early rather than late testing. Moreover, lay people need to understand that "choice of partners carefully is very risky", and that indeed the only sure way of proving HIV infection is VCT. These understandings could also increase the number of people seeking VCT for HIV.

The results of this study may be used for identification of beliefs that are of possible importance in decisions about undertaking VCT. It is not possible to draw definite conclusions about the relative importance of the various beliefs or about the variance explained by different determinants. Additional research needs to be conducted to study psychosocial factors associated with undertaking VCT in a quantitative way. The results of this study could be used to develop a questionnaire on psychosocial determinants for VCT that may be used in further quantitative research (probably with a much bigger sample of people who have tested for HIV). Nevertheless, these results can help VCT counsellors and educators in tailoring their education materials to the needs and beliefs of the target population.

\section{ACKNOWLEDGEMENTS}

To the research assistants: Miss Kyakuhaire, Miss Butungi, Mr. Mwebaze, Mr. Babikunyamu, and Mr. Matsiko who took part in the data collection. This study was financed by Case Western Reserve University Fogarty Program and Uganda Society for Health Scientists (USHS).

\section{REFERENCES}

1. Ministry of Health, AIDS Control Programme fourth quarter surveillance report 2000, Entebbe, Uganda.

2. Nuwaha, F. Sexually transmitted diseases in Uganda: implications for control. PhD thesis. Department of public health sciences, Division of International Health (IHCAR), Karolinska Institutet, Stockholm Sweden, 2000.

3. Wawer, J.M., Sewankambo, N.K., Serwadda, D. et al. Control of sexually transmitted diseases for AIDS prevention in Uganda: a randomised trial. Lancet 1999; 353:525-535.

4. Grosskurth, H., Mosha, F., Todal, J., et al. Impact of improved sexually transmitted disease treatment on HIV infection in rural Tanzania: randomised trial. Lancet 1995; 346:530-536.

5. Nuwaha, F., Faxelid, E. and Hojer, B. Predictors for condom use among patients with sexually transmitted diseases in Uganda. Sex Transm Dis 1999; 26:490-495.

6. Nuwaha, F., Faxelid, E., Neema, S. and Hojer, B. Lay people's perception of sexually transmitted infections in Uganda. Int. J. STDs \& AIDS 1999; 10:709-717.

7. Robinson, N.J., Mulder, D., Auvert, B., Whitworth, J. and Hayes, R. Type of partnership and heterosexual spread of HIV infection in rural Uganda: results from simulation modelling. Int. J. STDs \& AIDS 1999; 10:718-725.

8. Serwadda, D., Gray, R.H., Wawer, M.J. et al. The social dynamics of HIV transmission as reflected through discordant couples in rural Uganda. AIDS 1995; 9:745-750.

9. Ayiga, N., Ntozi, J.P.M., Ahimbisibwe, F.E., Odwee, J. and Okurut, F.N. Deaths, HIV testing and sexual behaviour change and its determinants in Northern Uganda. In Resistance to Behaviour changes to reduce HIVIAIDS infection 1999: 35-39. Eds. Caldwell, J.C., Caldwell, P., Anarfi, J., AwusaboAsare, K., Ntozi, J., Orubuloye, I.O., Marck, J., Cosford, W., Colombo, R. and Hollings E. Health Transition Centre, Canberra 1999. The Australian National University.

10. de Vries, H., Dijkstra, M. and Kuhlman, P. Self-Efficacy: The third factor besides attitude and subjective norm as predictor of behaviour intentions. Hlth. Educ. Res. 1988; 3:273-282.

11. de Vries G. and Backbier, E. Self-Efficacy as an important determinant of quitting among pregnant women who smoke: the Paltern. Prevent Med 1994; 23:167-174.

12. Nuwaha, F., Mulindwa, G., Kabwongyera, E. and Barenzi, J. Causes of low attendance at national immunisation days for polio eradication in Bushenyi district Uganda. Trop. Med. Int. Health 2000; 5:364-369.

13. Kaguna-Amoti, B. and Nuwaha, F. Factors influencing choice of delivery site in Rakai district of Uganda. Soc. Sci. Med. 2000; 50:203-213.

14. Nuwaha, F., Kambugu, F. and Nsubuga, P.S.J. Factors influencing sexual partner referral among patients with sexually transmitted diseases in Uganda. Sex. Transm. Dis. 1999; 26:483-489.

15. Nuwaha, F., Faxelid. E., Neema, S., Ericksson, C. and Hojer, B. Psychosocial determinants for sexual partner referral in Uganda: qualitative results. Int. J. STD \& AIDS 2000; 11:156-161.

16. Klepp, K.I., Ndeki, S.S., Theun, F., Leshabari. M. and Seha, A.M. Predictors of intention to be sexually active among Tanzanian school children. East Afr. Med. J. 1996; 73: 219 224.

17. Ndeki, S.S., Klepp, K.I. and Mliga, G.R. Knowledge, perceived risk of AIDS and sexual behaviour among primary school children in two areas of Tanzania. Hlth. Educ. Res. 1994; 9:13.3-141

18. Wilson, D., Lavelle, S. and Hood, R. Psychosocial predictors of intended condom use among Zimbabwean adolescents in probation/remand homes. AIDS Care 1990; 2:267-274.

19. Ajzen, I. The theory of Planned behaviour. Organ. Beh. Human Dec. Processes 1991; 50:179-211.

20. Henderlson, R.H. and Sundaresan, T. Cluster sampling to assess immunisation coverage with a simplified sampling method. Bull World Health Organ. 1982; 60:253-260.

21. Norusis, M.J. SPSS/PC for the IBM PC/XT/AT. SPSS Inc. Chicago, IL, 1988.

22. Green, E.C. The anthropology of Sexually Transmitted diseases in Liberia. Soc. Sci. Med. 1992; 35:1457-1468.

23. Krueger, R.A. Focus groups a practical guide for applied research. Newbury Park, CA: Sage publications, 1988.

24. Stewart, D.W. and Shamdasani, P.N. Focus groups: theory and practice. Newbury Park, CA: Sage publications, 1990.

25. Kleinman, A., Eisnberg, L. and Good, B. Culture Illness and care: Clinical lessons from anthropological and cross-cultural research. Ann. Intern. Med. 1978; 88:251-258. 